\title{
Acto de lectura y teología. Ensayo a propósito del lector en Génesis 1-3
}

\section{Reading act and theology. Essay on the Reader in Genesis 1-3}

\author{
Mike Van Treek \\ Pontificia Universidad Católica de Chile, Chile \\ mvan@uc.cl
}

- Resumen - Se propone analizar el rol del lector en la construcción del sentido del texto. Desde el supuesto teórico que la ficción narrativa produce un conocimiento de la realidad y es un registro válido para el trabajo teológico, se abordan una serie de episodios clave en la intriga de los tres primeros capítulos de la Biblia hebrea. El autor profundiza en algunos aspectos de la construcción del lector y cómo este es llevado por el narrador a formular una postura teológica frente al mundo que se despliega. Al mismo tiempo que el narrador estimula la confianza en el decir del personaje divino, el lector se ve llevado a considerar críticamente el andamiaje de sus creencias en relación a su historia, desplazándose hacia un verdadero ejercicio crítico de teología fuera del mundo del texto.

Palabras clave: narratología, puesta en escena, ficción, alteridad, Biblia hebrea.

- Abstract - In order to examine in depth some connections between theology and the concept of «Word of God», we analyse the reader's response in some selected pages of the biblical book of Genesis. We suppose that fiction results in the knowledge of reality and that is a valid framework to make theology. The narrator leads the narrative to take stance on the virtual world unfolded in front of reader. By doing so, the narrator invites the readers to share the God's points of view and to review his own theological and anthropological beliefs. The active reader of the Genesis exercises a very important job both in critical theology and critical thinking thanks to a cleverness narrative art.

Keywords: Narratology, Arrangement, Fiction, Alterity, Otherness, Hebrew Bible. 


\section{INTRODUCCIÓN}

El presente artículo pretende prestar servicio al debate sobre la relación entre teología y Palabra de Dios en el contexto del encuentro anual de la Sociedad Chilena de Teología realizado en Concepción en octubre del año 2009. Desde que el tema fue planteado en la sesión anterior, se entendía «Palabra de Dios» como una expresión más amplia que «Sagrada Escritura». La mesa directiva de la Sociedad me ha pedido que, desde mi enfoque metodológico, proponga una reflexión sobre la temática. Luego de intentar otras aproximaciones, me ha parecido pertinente -espero poder llevar a mis lectores y lectoras a un juicio similar- proponer el análisis de un aspecto específico y crucial del acto de interpretar textos escritos: el lector ${ }^{1}$. En su trabajo hermenéutico, se da una complejidad que permite hacer dialogar y discutir la acción de Dios tal y cual él la cree, confrontándola con las que la narración propone en sus diversos niveles de enunciación. Para lograr este cometido, me propongo analizar la construcción textual del lector en los primeros capítulos del Génesis, buscando provocar una reflexión sobre la forma en que el relato lo obliga a tomar postura en el mundo del texto y en su propio comportamiento. Nuestro horizonte no es meramente exegético; nos interesa ahondar en un diálogo.

Los estudios bíblicos atraviesan por un período agitado debido, en parte, a que desde hace más de un siglo se han desarrollado en el horizonte de un trabajo interdisciplinar cada vez más plural y masivo. La diversidad de miradas, métodos y supuestos teóricos hoy es enorme. Ninguno de ellos goza de una legitimidad innata, ni está en posición de conceder a otro una carta de ciudadanía como método válido para la exégesis bíblica. Pero este panorama no es desalentador ni desconsolador. Por una parte, es síntoma de vida y de creatividad entre los teólogos, exégetas y, en general, entre la comunidad científica, que de una u otra forma tocan o se adentran en el amplio mundo de la Biblia. Por otra, al producirse cambios disciplinarios profundos se genera una cierta incertidumbre en relación a los consensos previamente establecidos. Estos cambios ocurren en o desde el interior de cada campo de estudio bíblico. En relación a lo primero, el caso del estudio crítico del Pentateuco tiene mucho que enseñarnos. En esta línea se nos impulsa a un optimismo esperanzador en relación a las nuevas perspectivas y métodos fundados en el paradigma que sustituyó la primacía de lo diacrónico por el interés en la forma final del texto canónico (Rendtorff). En relación a lo segundo, señalemos que las disciplinas que antiguamente recibieron el nombre de «disciplinas auxiliares» de la exégesis, hoy representan focos de investigación en la compleja red de generación de conocimientos científicos o académicos sobre la Biblia y otros corpora. Hoy cualquier manual de interpretación bíblica considera a fondo la cuestión de los métodos y las

\footnotetext{
Para la publicación de este artículo he tomado en cuenta algunos de los comentarios aportados por los colegas en la sesión previamente mencionada, así como también el nuevo destinatario del escrito.
} 
aproximaciones. Un ejemplo claro lo representa Barton (2001), que pasa revista a una serie de aproximaciones que ingresan al concierto de interpretaciones bíblicas en los últimos treinta años y que se han ido transformando en la medida en que los cánones de saberes de otras disciplinas se transforman. En la misma línea nos impulsa el ya conocido documento La interpretación de la Biblia en la Iglesia, de la Pontificia comisión bíblica.

El panorama actual de la exégesis puede provocar una cierta sensación de desazón frente a otras disciplinas teológicas que ven en el cambio de paradigma una dificultad para aplicar los resultados de los nuevos métodos a las síntesis más asentadas. Esta incomodidad, en todo caso, no puede resolverse echando marcha atrás; una sola lectura histórico-crítica de la Biblia parece insuficiente para sustentar una tarea de hermenéutica teológica relevante para hombres y mujeres de hoy. Para resolverla o elaborarla hay una condición inicial fundamental: regresar al texto. Creo que en esta dirección pueden ser tomadas las siguientes palabras: "Lo que ahora necesitamos no son nuevas hipótesis sobre el Sitz im Leben, sobre posibles fuentes o sobre el proceso de su transmisión [... sino] regresar al texto y distinguir entre las hipótesis fecundas y aquellas que no lo son» (Ratzinger 57).

Como sea, aquello que parece bastante claro es que una renovación de la exégesis bíblica en el campo de la educación teológica -de cara al ejercicio mismo de la teología y más ampliamente en relación a su pertinencia intelectual y académica- es necesaria, so pena de perder tanto la capacidad de diálogo interdisciplinar y como la de recuperar de un cierto déficit teológico de los estudios demasiado centrados en hipótesis «excavativas» (Alter, The Art of Biblical Narrative 13) o arqueologizantes sobre los textos bíblicos.

El riesgo de no innovar en el ámbito de la educación teológica es grande. Renunciaríamos, en gran parte, a hacernos cargo de los problemas de hombres y mujeres que llegan a la Biblia con un interés renovado, a partir de las transformaciones que está viviendo nuestro mundo y nuestras sociedades. Con paradigmas basados en la historia de las ideas, no podemos entrar en estos nuevos senderos sino de manera superficial, ¿cómo podrían los resultados de los estudios bíblicos excavativos hacer frente a las preguntas planteadas al hombre de hoy a propósito del cambio climático, de las transformaciones de la economía o de las profundas modificaciones en las concepciones de familia, afectividad, sexualidad e intimidad? En este concierto de métodos, el análisis narrativo se ofrece como una opción válida y fructífera no solo para la comprensión del texto bíblico, sino que para el diálogo con otras disciplinas teológicas; esta no es una conclusión nueva en nuestro campo de estudios (cfr. Gesché).

En las páginas siguientes, luego de presentar brevemente el método intentaré mostrar cómo este puede prestar servicio en la relación entre teología y Palabra de Dios en un aspecto específico del problema, a saber, la cuestión del lector como mecanismo hermenéutico. 


\section{EL ANÁLISIS NARRATIVO}

\subsection{Supuestos teóricos}

Suele llamarse "análisis narrativo» a un conjunto de procedimientos que aplica, a la lectura e interpretación de la Biblia, diferentes modelos de comprensión del acto de lectura derivados de la crítica literaria moderna. Si hace unos años fue necesario justificar que era un método válido y teológicamente pertinente, ya no se cuentan los estudios realizados en esta perspectiva y su valor en el horizonte de la teología, de la fe y del sentido aparece plenamente justificado en ellos ${ }^{2}$.

Dentro de los supuestos teóricos del método, destaco los más importantes. En primer lugar, el método se basa en la distinción fundamental entre historia y enunciación o entre qué se cuenta y cómo se cuenta. El análisis narrativo se interesa a las diversas maneras en que los narradores pueden enunciar una misma cosa contada. En segundo lugar, y como consecuencia, hay que aceptar que el narrador relata desde un punto de vista; lo hace seleccionando en virtud de unos intereses y disponiendo los elementos de la historia de una manera particular. Haciendo esto, el narrador, en tercer lugar, busca comunicar contenidos y producir en el lector una serie de efectos o respuestas que integran diversos niveles de la actividad cognitiva, como el complejo mundo emocional. En cuarto lugar, esto implica que el narrador posee una estrategia al contar la historia mediante la cual busca introducir o implicar al lector en el mundo del relato. Desde esta perspectiva, el texto no está completo sin el lector, porque el acto de lectura es un juego estratégico de previsiones y anticipaciones (Eco 50-6). Así, el sentido de un texto se construye en una relación entre texto y lector. En virtud de la estrategia narrativa, el lector no queda abandonado en un caos interpretativo, sino que es guiado por un cierto camino que el narrador astutamente puede balizar con señales más o menos explícitas. Finalmente, en el mundo del texto, construido por el narrador, hay ciertas «reglas de verosimilitud» que pueden ser muy distintas a las reglas de credibilidad de los relatos historiográficos. Esto significa que el narrador construye un mundo coherente haciendo de la ficción un mundo semiaparte del mundo que el lector real experimenta normalmente; como dice Juan José Saer, un signo significa cosas diferentes según sea la tela narrativa que lo envuelve (cfr. Saer 176). Volveré más tarde sobre esto último.

2 Dentro de los iniciadores de esta línea de investigación hay que citar a Alter, que llega a los estudios bíblicos desde la literatura moderna pero luego ha seguido publicando estudios en el campo de la Biblia hebrea. Otros estudios pioneros de importancia son: Gunn (1980), Bar-Efrat (1984), Sternberg (1985), Ska (1990). No faltan las teorizaciones y sistematizadores de diversas maneras de ejercer y aplicar el análisis: Fokkelman (1999), Marguerat y Bourquin (2000), Ska, Sonnet y Wénin (2001). En el ámbito francoparlante, se ha desarrollado una Red de Investigaciones en Análisis Narrativo de la Biblia (RRENAB, por sus nombre en francés) conformada por facultades de teología, católicas y protestantes, de Europa y Canadá. 


\subsection{La movilidad interpretativa del lector}

Como hemos enunciado más arriba, el análisis narrativo toma en serio la cooperación interpretativa del lector, pues así como inerte es una partitura musical que no se ejecuta, muerto está un texto que no encuentra un lector que lo interprete. El supuesto teórico fundamental de este ensayo es que el lector es impulsado a recorrer y a moverse en diferentes niveles en el acto de lectura; en esa acción del lector se produce la creación del sentido del texto. Para que este movimiento sea posible se requieren espacios, distancias o alteridades que visitar. Un párrafo de Barthes lo dice con convicción:

Ce lecteur, il faut que je le cherche (que je le «drague»), sans savoir où il est. Un espace de la jouissance est alors créé. Ce n'est pas la «personne» de l'autre qui m'est nécessaire, c'est l'espace: la possibilité d'une dialectique du désir, d'une imprévision de la jouissance: que les jeux ne soient pas faits, qu'il y ait un jeu. (Barthes 10-1).

Esa dialéctica del deseo se constituye en parte porque emergen en el texto elementos en tensión irresuelta. Hay distancias que se crean porque el texto y el lector se sitúan en emplazamientos diferentes: la distancia es condición de interpretación, no está todo dicho. Al contrario de los métodos histórico-críticos que teorizaron este hiato como dificultad, la narratología lo recoge como posibilidad (¿habría que decir condición?) de interpretación. Una de las consecuencias para la relación entre exégesis y teología es que todo lector hace teología, porque todo lector está obligado a tomar una postura frente al mundo que se le despliega con múltiples maneras de representar la relación entre Dios y los humanos. A diferencia de lo que los métodos histórico-críticos proponían -una es la interpretación correcta porque esta debía coincidir con la intención del autor original que el exégeta debe reconstruir históricamente (la óptica Schleiermacher-Dilthey) (cfr. Mura 169-217)-, en el supuesto teórico que hemos descrito brevemente, el lector puede encontrar más de un espacio de lectura y tiene más margen interpretativo, aunque esto no significa la supresión de todo límite ni la creación de lo que pueden llamarse "campos interpretativos», en los cuales ciertas posturas puedan validarse más fácilmente que otras.

En este ensayo quisiera proponer una exploración práctica de esos espacios que el lector va encontrando y que le permiten ir construyendo un sentido del texto. La lectura de los textos bíblicos propuesta no es, obviamente, la única posible, pero se basa en una lectura minuciosa del texto original en su forma final. Aquello que resulta original y propio de este ensayo no es la lectura de los pasajes bíblicos en sí. En ella, hemos seguido la guía de Wénin, autor que nos parece minucioso y creativo, sobre todo en su reciente obra (D'Adam à Abraham ou les errances de l'humain). Él persigue un fin similar al aquí expresado: poner de relieve la pertinencia de los relatos bíblicos para el hombre de hoy. Lo hace a partir de una lectura de los principios del análisis narrativo. 
Los espacios que exploraremos en este escrito están determinados por la tensión entre el comienzo y el desenlace, entre el punto de vista del narrador y de los personajes, así como la distancia implícitamente reconocida por el narrador con su lector, es decir, con quien pretende ser informado y afectado en la lectura. Que como lector se acepte ese movimiento y esa tensión, implica aceptar la existencia de un espacio que el sujeto no puede llenar totalmente. Leer es aceptar una pérdida: querer decir lo definitivo del texto. Tal aceptación es el umbral de la significación del misterio. Supongamos entonces que una teología puede comenzar a la hora en que el lector se sumerge en el relato, en la poesía o en la instrucción.

Testimonio y vestigio de lo que un pueblo cree que es la acción de Dios en la historia, sobreabundancia de significado, esas son las coordenadas propuestas para la lectura de la Biblia. Así recibo las letras siguientes:

La Revelación es un proceso dinámico entre Dios y el hombre que se hace nuevamente realidad solo en el encuentro. La palabra de la Biblia testimonia la Revelación; pero no la contiene de modo tal que pueda agotarla en sí misma o que pueda metérsela al bolsillo como un objeto. La Biblia testimonia la Revelación en cuanto tal la sobrepasa. En la práctica esto quiere decir que un texto puede significar mucho más de lo que su autor estaba en capacidad de pensar (Ratzinger 53).

Quiero proponer que el texto adquiere sentido en la medida en que el lector transita por los diversos niveles enunciados más arriba. El texto acoge al lector en sus espacios y lo guía por sus paisajes a la manera en que un niño lee un libro troquelado, donde al abrir cada página los personajes y el escenario literalmente emergen del plano estático; el lector no puede dejar de recorrer con la mirada los diversos planos, de lo contrario abandona su rol y la posibilidad de comprensión ${ }^{3}$.

\subsection{La construcción del mundo: ficción, heurística y credibilidad}

Retomemos una idea anteriormente enunciada. El análisis narrativo explora y analiza la forma en que el narrador dispone los eventos (l'agencement) para producir una cierta batería de efectos sobre el lector. Si el narrador dispone los elementos del relato en virtud de la búsqueda de un impacto sobre el lector, significa que la narración instala un discurso, una teología que surge en el acto de lectura y no una teología que se extrae del análisis exegético. Parece pertinente recordar en este punto la distinción entre «relato» y «narración», en tanto que el primero es el discurso textual y el segundo es «el hecho en sí de contar», lo que implica necesariamente un lector (cfr. Genette 12). De esta forma, la ficcionalización es un acto que produce conocimiento teológico en la medida en que los efectos del texto mueven al lector a tomar postura dentro del agencement de los discursos que remiten, de varias formas y en múltiples enunciadores, al personaje divino y a su referente. No basta, por así

El símil con el libro troquelado fue la primera imagen que Alberto Toutin me transmitió cuando le presenté brevemente el plan de este ensayo; me parece acertada para representar la acción lectora. 
decirlo, creerle al narrador del texto, como si bastara lo que él dice del personaje divino (tampoco basta lo que Dios, como personaje del texto, dice de sí mismo). Lo que resulta productor de sentido es el espacio de movilidad entre el enunciado del narrador y los otros aspectos del relato, como los personajes (entre ellos el divino). El mismo narrador es, además, movible, y su punto de vista está lejos de ser un referente fijo para el lector. Así lo plantea Sonnet en un enunciado que abre esta forma de ver el texto bíblico en un espacio teológiamente cultivable:

Le point stable, qui sert de point d'Archimède au narrateur, est donc aussi un point de mouvant, et il est intérieur au récit. Voilà qui oblige à repenser l'omniscience divine comme indissociable du récit de son effectuation, et celle du narrateur comme omniscience a posteriori (celle de l'historien qu'il est aussi), s'ajustant à la courbure de la «science» divine. Le point de vue du narrateur devient ainsi mobilis in mobile, à l'instar du Nautilus de Jules Verne. Un tel modèle a apparemment de quoi parler à un âge intellectuel formé par la théorie de la relativité, par la doctrine du cercle herméneutique et par diverses formes de pensée dynamique, sensibles à la dimension processuelle de la réalité (Sonnet 259).

En virtud de un proyecto, el narrador crea un mundo: «es jefe de todo el circo» (Fokkelman 55). Navajas habla incluso de una normativa social diferente a una normativa ficcional. La normativa ficcional es independiente de la realidad y tiene la capacidad de crear nuevos códigos (cfr. Navajas 65-6), cuya coherencia da a la obra su carácter verosímil. Un cierto gesto del relato es verosímil, creíble en el mundo del relato, en la medida que logre convencer al lector que tal gesto es posible dentro del marco definido por el mismo relato.

En ese mundo, los signos se reenvían los unos a los otros creando una red de significados. Dentro de esos escenarios verosímilmente ficcionales, el narrador coloca personajes, entidades virtuales que funcionan como las personas. En ese mundo creado, el narrador se permite "connaître des choses qu'on ne saurait connaître ni dans le monde réel ni dans les récits ayant comme finalité une représentation du monde réel, à savoir tout ce qui relève de la vie intérieure de ses personnages» (Cohn 33). En el ámbito bíblico, Alter señala lúcidamente:

A los escritores bíblicos la ficción les sirve fundamentalmente como un un instrumento para conocer profundamente las perplejidades fijas del hombre en su condición de criatura [...] La imaginación ficticia, que reune una amplia gama de medios narrativos, complicados e íntegros, desarrolló una forma fundamental para lidiar con este difícil sentido. Mediante el uso de la ficción, de esta manera, los escritores bíblicos han legado a nuestra tradición cultural un recurso sólido para la Biblia hebrea, y hemos de ser capacaces de poseer su visión de manera más completa a través de una mejor compresión de las condiciones distintivas del arte por el cual trabaja. (Alter, The Art of Biblical Narrative 175-6, la traducción es nuestra) ${ }^{4}$.

$4 \quad$ Fiction fundamentally serves the biblical writers as an instrument of fine insight into these abiding perplexities of man's creaturely condition [...] The fictional imagination, marshalling a broad array of complicating and integrating narrative means, provided a precious medium for making this sort of difficult sense. By using fiction in this fashion, the biblical writers have bequeathed to our cultural 
De esta forma, la ficción no se presenta aquí como una alternativa a lo real, sino como una forma de explorar y de exponer lo real. De lo anterior se colige que el registro de la ficción no está reñido con el registro de lo teológico, sino muy por el contrario, es una impostación apropiada para impulsar una especulación teológica y antropológica. Así también lo recibe Ricœur, al reflexionar sobre el «modo narrativo» como registro teológico que se engendra cuando se afronta la libertad divina con la libertad del humano; encuentro paradójico en el cual el proyecto de Dios (unitario, estable) se enfrenta con el humano particular, que debe articular individualmente (cfr. Ricœur 18-9). Ricœur aplica esta idea al relato de la pasión, a partir del concepto de «prosa historiográfica de ficción» planteado por Alter en su trabajo ya citado.

Para que esta exploración tenga oportunidad de sostenerse, el relato debe recurrir a un sistema de signos plausible. En otras palabras, el narrador debe ser capaz de crear un mundo que, en sí mismo, funcione de forma congruente. Las reglas de funcionamiento de ese mundo serán, con bastante frecuencia, diferentes al mundo experimentado por el lector, no únicamente por una distancia cultural entre el ambiente originario del texto y el lector moderno, sino por el registro mismo de lo ficcional que adopta -sin poca frecuencia- el tono de lo fantástico. Lo realmente importante, como señala Macdonald, es que los elementos de esa sintaxis narrativa ficcional provengan del mismo sistema (cfr. Macdonald 227). La autora concibe la obra narrativa como un dispositivo creado por el autor que tiene un funcionamiento autónomo del mundo real. En toda esta refiguración, la intriga o trama da a esta serie de elementos aislados la existencia como objetos organizados y creíbles.

Volvamos brevemente sobre un punto anterior: el registro de lo fantástico. La ficción y lo fantástico tienen, entre muchos, la «mala fama» de ilusionar al lector sacándolo de su realidad. Pero es posible ver en la ficción y la fantasía todo lo contrario: una forma de conexión con la realidad bajo la forma de "¡esto no sucede así en mi mundo!, ¿cómo sucede esto en mi mundo?» superando así la dicotomía entre una lectura alegórica y otra literalista (Donaldson 27).

\section{LOS ESPACIOS EN GÉNESIS 1-3}

De los muchos espacios que el texto deja para el lector, algunos son particularmente interesantes de analizar para asentar una lectura teológica de los textos que presentaré. En este ensayo pondré en evidencia los espacios que se crean para el lector en relación a la tensión narrativa que se origina en el relato (inicio-desenlace) y las diversas distancias establecidas entre los enunciados del narrador, los personajes (incluido el personaje divino) y el lector.

Pretendemos mostrar el funcionamiento de este supuesto leyendo algunos episodios de los tres primeros capítulos de la Biblia. El interés para el tema del encuentro 
queda puesto de relieve en el hecho que la creación del mundo y del hombre son puestos en escena mediante un rol preponderante del habla de Dios. Este fenómeno nos dispone, ya desde lo más profundo, a considerar el lenguaje como un dominio productor de sentido. Al mismo tiempo, al profundizar en una lectura minuciosa del texto, el lector descubrirá que la palabra humana y divina conforman una verdadera intriga de representaciones y tensiones. En gran medida, el arco literario de los tres primeros capítulos del Génesis está marcado por el rol de diversos discursos entre los cuales el lector debe encontrar y reconocer su lugar y, en definitiva, elaborar el suyo.

\subsection{El espacio fundamental: intriga y transformación}

Hay múltiples transformaciones en el relato. Considerable es la tensión que se produce en el contraste entre Génesis 2, 15-17 y Génesis 3, 11-13:

${ }^{15}$ Y Adonay Elohim tomó al humano y lo dispuso en el jardín de Edén para trabajarla y custodiarla. ${ }^{16}$ Y Adonay Elohim ordenó al humano diciendo: «De todos los árboles del jardín comer comerás. ${ }^{17}$ Pero del árbol de conocer bien y mal tú no comerás, porque el día en que tú comas, morir morirás». (Génesis 2, 15-17).

11b [Adonay Elohim] dijo: «¿Quién te ha contado que estás desnudo? ¿Del árbol del que yo te dije no comer has comido?». ${ }^{12} Y$ el humano dijo: «la mujer que tú me diste conmigo, esa me dio del árbol y yo comí». ${ }^{13}$ Y Adonay Elohim dijo a la mujer: «¿Qué has hecho?» Y la mujer dijo: «Fue la serpiente que me engañó y comí». (Génesis 3,11-13).

Que estos dos episodios sean dos polos del relato parece justificado por el hecho que se trata de la transgresión, al menos parcial, de las primeras palabras de Dios al hombre. Las consecuencias al nivel del relato son importantes, como se puede concluir, por la reacción del personaje divino en los versículos que le siguen (Génesis 3, 14-19). Estamos frente a un espacio abierto por el relato, el cual debe ser recorrido por el lector. El espacio se marca con preguntas: ¿cómo es que el humano ha llegado a transgredir el precepto originario?, ¿qué fuerzas lo han llevado a ello?, ¿qué ha pasado en el camino del humano naciente?, ¿qué y a quién debemos creer en el relato?, ¿qué transformaciones en el plano de las representaciones de Dios y del humano han tenido lugar?, ¿qué importancia tiene haber comido del fruto?, ¿es un Dios que sanciona por medio del tabú? Estas y otras preguntas invitan al lector a pensar, a explorar las entidades narrativas que se le despliegan.

Un espacio intrigante es un espacio de pensamiento especulativo. La tensión inicio / desenlace hace que las estructuras cognitivas funcionen para buscar un sentido - un ajuste- a lo que lee. Cuando decimos especulativo lo decimos en su sentido más original, el lector mira, observa: encuentra su posición en relación a un despliegue que él no controla y que no le pertenece, pero que suscita en él un deseo de habitación y comprensión. El relato provoca en el lector la actitud de evaluar si la posición que toma como lector es adecuada o no a lo que el texto va enunciando. La previsión que se despliega allí implica una actitud cognitiva activa en relación 
a los prejuicios con que el lector se acerca y su verificación (o no) constante en el conjunto del relato. En el caso preciso que nos ocupa en esta sección, la pregunta por la lectura interpretativa coherente tiene en su núcleo la cuestión de la relación entre Dios y el hombre. La especulación teológica entonces es provocada por el mismo texto narrativo, porque de otra forma sería imposible un funcionamiento correcto de él. Eco dirá que: "prevedere il proprio Lettore Modello non significa solo "sperare» che esista, significa anche mouvere il testo in modo da costruirlo» (Eco 56).

\subsection{El lector entre el narrador y el personaje}

En un libro lleno de sugerencias y sutilezas interpretativas, Balmary reflotó un detalle que muchos lectores de la Biblia habíamos pasado por alto o al que le habíamos prestado alguna importancia mayor en la elaboración de sentido. El detalle, sin embargo, había sido tratado largamente en la tradición judía y cristiana (Balmary). En Génesis 1, 26-28, el texto bíblico propone:

26 Y Elohim dijo: «Hagamos humano en nuestra imagen, como nuestra semejanza, que ellos dominen el pez de la mar y el ave del cielo y el ganado y toda la tierra y todo reptil que repta sobre la tierra».

${ }^{27}$ Y Elohim creó al humano en su imagen, en imagen de Elohim lo creó, macho y hembra él los creó. ${ }^{28}$ Y Elohim los bendijo y Elohim les dijo: «fructifiquen y multipliquen y llenen la tierra y sométanla y dominen el pez de la mar y el ave del cielo y todo viviente que repta sobre la tierra» (Génesis 1, 26-28).

Leído atentamente el texto presenta una variación significativa que afecta la forma en que el personaje divino enuncia su acción y la forma en que el narrador informa la manera en que ella ha acaecido:

Elohim: Hacer (plural). Imagen-semejanza.

Narrador: Crear (singular). Imagen-imagen.

La repetición no carece de importancia puesto que, en este relato, la estructura se sostiene gracias a ella. El proyecto de Elohim se expresa bajo el verbo «hacer» al humano en imagen y semejanza. El narrador, voz confiable del relato, enuncia la realización del proyecto de una forma diferente. Según esta voz omnisciente, Elohim «crea» al humano según su imagen, enfatizando mediante la repetición esta última palabra. Si hay espacio entre estas dos formas de enunciar la acción es necesario que el lector se pregunte la razón de tal desplazamiento.

La tradición judía había anotado esta diferencia interpretándola en un tono apologético. Así, R. Simlay, señala: "Aquí no está escrito "y crearon dioses al hombre», sino «y creó Dios» (cfr. Vegas Montaner 8,9). A partir de esta diferencia se han escrito muchas páginas con diversas interpretaciones (véase las varias posturas en Colodenco 
26; y otras interpretaciones de orden exegético en Hamilton 132-4). Para Gándara, se trata de Dios que saca desde adentro de sí mismo un interlocutor distinto (242-7).

Los verbos «hacer» $\mathrm{y}$ «crear» no tienen en hebreo una relación de sinonimia entre sí, sino hiperonimia: crear (hipónimo) es una clase de hacer (hiperónimo). Tampoco «imagen» es equivalente a "semejanza» ¿Qué sentido puede tener la diferencia entre el proyecto divino y el reporte del narrador?

Según Wénin, la solución más respetuosa del texto es la siguiente. Elohim expresa su intensión de hacer la humanidad con un verbo en plural. Dios habla a alguien y ese no pude ser sino la misma humanidad que está creando, de la misma forma que en los versículos anteriores su palabra produce el mundo habitable: 1, 3 (luz); 1, 6 (firmamento); 1, 9 (aguas inferiores); 1, 11 (vegetación); 1, 14 (astros); 1, 20 (seres marinos y aves); 1, 24 (animales terrestres). Elohim se refiere a este proceso como un «hacer» de tipo general (hiperonimia), pero el narrador solo enuncia una parte de este actuar divino-humano, por ello utiliza un verbo hipónimo, más específico: «crear», un verbo que en la Biblia hebrea solo lleva a Dios como sujeto. En efecto, solo Dios puede «crear» algo nuevo (cfr. Wénin, «Dieu qui visite la faute des père sur les fils» 40).

La diferencia no está solo en la forma de enunciar la acción, sino también en la manera en que esta se especifica. Elohim anuncia su intención de hacer «en imagen y semejanza», mientras que, esta segunda, en el reporte del narrador, está ausente. $\mathrm{Si}$ «imagen» (s.elem) significa «figura, estatua, representación», la palabra «semejanza» (demût) tiene un significado bastante más abstracto: «parecido». Para despejar dudas, hay que decir que los comentarios son bastante claros en este punto (cfr. Westermann 146).

Siguiendo a Wénin, el narrador enunciaría que una parte del hacer (plural) divino quedaría inacabada, no terminada por Elohim quien crea (singular) en imagen. Quien debe culminar el hacer humano según la semejanza es la propia humanidad, devenir imagen de Dios es una tarea, una vocación, un camino, un devenir histórico (cfr. Wénin, D’Adam à Abraham y El hombre bíblico). Esta página bíblica ha dado que pensar desde muy temprano en la tradición. Orígenes y Basilio de Cesarea lo comentan en la línea del hombre inacabado. Véase la recuperación de la tradición en Balmary, aunque su interpretación difiere en el final: la semejanza no está en el hacerse voluntarioso del humano sino en compartir cierta dimensión de increatura con el increado (cfr. Balmary 101-6).

Un elemento más del texto: la humanidad es creada en cierta correlación con el mundo animal. En efecto, los animales y la humanidad son creados durante el sexto día. La importancia de esta sincronía está dada por la rigurosa repetición de la fórmula: "fue una tarde y fue una mañana. Número de día» luego de cada acto creador. Además de ser creados en el día sexto, la humanidad comparte con los animales la misma bendición de abundancia y poblamiento (Génesis 1, 22-28). La expresión sexuada de ambas especies es similar ya que son "creadas macho y hembra» categorías genéricas que comprenden la diferencia sexual animal (cfr. Brenner 1997). 
Esto sugiere que para el texto bíblico la animalidad no es exterior al humano, sino parte de él. Así, el mandato de dominar sobre todo animal de la tierra (cfr. Génesis 2,28 ) dice también algo sobre la forma en que el humano se debería relacionar con su propia animalidad interior y no solo sobre una realidad exterior a él.

En esta línea, un ejemplo puede ser valioso. Cuando Caín entra en crisis frente a su hermano Abel, Adonay le dirige una palabra reveladora en este sentido: «el pecado está agazapado [rbs.], contra ti su avidez», una expresión que metaforiza el ávido acecho del mal como un animal listo para saltar en contra de la presa que desea (cfr. Alonso, ¿Dónde está tu hermano? 33). La cuestión se vuelve a abordar más adelante a propósito de la serpiente y su diálogo con la mujer.

Este asunto sugiere que la semejanza que el humano inacabado debe realizar no tiene una única posibilidad de constituirse. Puede asemejarse a Dios o al animal y así lo ha visto Beauchamp, quien afrontará la cuestión de la deformación animal de Dios y del humano como una manera de tematizar la relación entre violencia e idolatría (cfr. Beauchamp, sobre todo el capítulo cuarto). Si tal es la situación de la humanidad, su devenir histórico será, en parte, la historia de su libertad entrecruzada con la de otros.

Tres breves conclusiones para el trabajo del lector que lo impulsan hacia una apropiación teológica del acto de lectura. En primer lugar, el lector debe asumir un punto de vista evaluativo de la diferencia entre el proyecto divino y el reporte de su implementación por el narrador. Esta actitud se da no solo de cara a la intriga, sino también en relación a su propia experiencia en la implementación del proyecto humano.

En segundo lugar, debemos situarnos frente a un lector real y actual que ha leído el Génesis y lo cree demasiado conocido; con frecuencia mal impreso en su memoria, el lector pasa rápidamente por los sutiles y no tan sutiles relieves del tejido producido por el narrador. En este sentido, gran parte del trabajo de Balmary es el testimonio de su proceso de transformación como lectora. Reivindica así el estudio de los efectos del texto en sí misma. El lector real aprende de esta forma a respetar una alteridad que es el texto, un ser vivo que tiene al frente y con quien dialoga pero que, aún poniendo sus propias preguntas, deja que el texto exhale sus respuestas. En tercer lugar, leer la historia de «la humanidad» es leer su propia historia y leerse como una creatura increada en una encrucijada constante y esencial en la vida: sus opciones (de)forman la semejanza.

\subsection{Narrador fiable, narrador vulnerable: el espacio para la evaluación}

Si la humanidad (macho y hembra como los llama el texto) queda creada por Dios, pero debe completarse en el devenir histórico, la bendición de Elohim (Génesis 1,28 ) y la dieta otorgada (Génesis 1,29) pretenden asegurar que el ser humano puede orientarse al cumplimiento de esa vocación originaria. Culmina luego el trabajo de 
la creación durante el séptimo día (cfr. Génesis 2, 2), indicando así que el reposo, pese a no ser trabajo, es parte del proceso de crear. Así, tanto la humanidad como el resto de la obra divina quedan abiertas a una plenitud posterior.

No es difícil imaginar que si las primeras páginas de la Biblia hebrea plantean de esta forma el proyecto de humanidad, ella también hará lo posible para poner en escena los probables caminos de esa empresa, tanto en sus salidas airosas como en los fracasos 5 . Si estos son más frecuentes en la Biblia es porque le interesa mostrar las vías por las cuales transita la violencia y el mal (cfr. Wénin «De la violence à l'alliance...»), pero no faltan los textos donde el final de los relatos da cuenta de una profunda sabiduría humana, exitosa en su búsqueda de plenitud como en la historia de José y sus hermanos (Génesis 37-50) donde la fraternidad es (re)construida desde la raíz para que sea algo concreto y constatable (Alonso ¿Dónde está tu hermano? 257-319; Wénin, Joseph ou l'invention de la fraternité).

Más adelante en el relato, en el capítulo segundo, el narrador sitúa al lector frente a un escenario mucho más rico en descripciones físicas que el anterior. Estimula en el lector una capacidad plástica de imaginar y observar lo imaginado. Si la crítica histórica ha resaltado las diferencias entre los dos capítulos, aquí nos interesa realizar una lectura más continua de ellos, aunque no podremos detenernos en el examen de la cuestión. La continuidad de los dos episodios, pese a su diverso origen, está reforzada, además, por la intervención explícita a nivel redaccional utilizando una fraseología sacerdotal (v.4b) para introducir un relato que no lo era (cfr. Hamilton 150-2). Así, también en Génesis 2, 4-25 hay una exploración antropológica de la vocación fundamental de la humanidad. Leemos:

${ }^{7}$ Y Adonay Elohim modeló el humano, polvo fuera del humus, y le sopló en sus narices un aliento de vida y el humano llegó a ser un ser viviente. ${ }^{8} \mathrm{Y}$ Adonay Elohim plantó un jardín en Edén, al oriente, y colocó en él al humano que había modelado. ${ }^{9} \mathrm{Y}$ Adonay Elohim hizo germinar fuera del humus todo árbol deseable para la vista y bien para comerlo, y el árbol de la vida al medio del jardín y el árbol de conocer bien y mal.

${ }^{15}$ Y Adonay Elohim tomó al humano y lo dispuso en el jardin de Edén para trabajarla y custodiarla. ${ }^{16}$ Y Adonay Elohim ordenó al humano diciendo: «De todos los árboles del jardín comer comerás, ${ }^{17}$ pero del árbol de conocer bien y mal tú no comerás, porque el día en que tú comas, morir morirás».

${ }^{18}$ Y Adonay Elohim (se) dijo: «No es bueno que el humano esté solo. Yo haré para él un auxilio como su cara a cara». ${ }^{19} \mathrm{Y}$ Adonay Elohim modeló fuera del humus todos los vivientes de los campos y todas las aves de los cielos y (los) hizo venir hacia el humano para ver como les llamaría; y como les llamara el hombre (a un) ser vivo (sería) su nombre.

Véase, por ejemplo, los trabajos siguientes: Mirguet (2003), Di Pede (2007), van Treek Nilsson (2007), que desarrollan una perspectiva narrativa y antropológica sobre los caminos de la vida humana y aprovechan la cuestión del fracaso del hombre para proponer pistas de vida en común. 


\footnotetext{
${ }^{20} \mathrm{Y}$ el humano puso nombres para todo el ganado y para las aves del cielo y para todos los seres vivos de los campos; pero para el humano él [Adonay Elohim / el humano] no encontró auxilio como su cara a cara.
}

${ }^{21}$ Y Adonay Elohim hizo caer un sueño sobre el humano que se durmió y él tomó uno de sus lados y cerró la carne a su lugar. ${ }^{22}$ Y Adonay Elohim construyó el lado que él había tomado del humano en mujer y la hizo venir hacia el humano. ${ }^{23} \mathrm{Y}$ el humano se dijo:

«iEsta, esta vez, es hueso de mis huesos y carne de mi carne; a esta se le llamará «mujer» porque de «varón» ha sido tomada esta!» ${ }^{24}$ Por eso hombre abandonará su padre y su madre y se unirá a su mujer y ellos serán una carne única. ${ }^{25} \mathrm{Y}$ ellos dos estaban desnudos, el humano y su mujer, y ellos no se hacían vergüenza (Génesis 2, 7-25).

Este texto, normalmente leído como un feliz encuentro entre la mítica pareja humana originaria, podría encerrar alguna otra lectura que nos interesa rescatar para comprender la forma en que el devenir del humano es puesto en escena. Una lectura divergente a esta conclusión emerge cuando el lector es capaz de discernir la doble enunciación de un mismo evento: la del narrador omnisciente y fiable y la de un personaje con conocimiento limitado, el varón. Resaltamos cuatro elementos (el primero nos tomará más espacio), más un quinto en la sección siguiente.

En primer lugar, constatamos que la humanidad es creada de una forma diferente a la forma en que se enuncia en Génesis 1,27 , no es «macho y hembra», sino simplemente una humanidad sexualmente indiferenciada. En efecto, el término hebreo utilizado (?āāam) significa «humanidad» y solo esporádicamente puede indicar, y de forma ambigua, a un humano singular (cfr. Halot). En la tradición judía encontramos que se juega con los géneros masculino y femenino de polvo y humus, de forma en que el humano contiene inicialmente lo masculino y femenino amalgamado. Entre los comentaristas modernos, Westermann -con bastante información y análisis de los diversos significados- concluye que se trata de la humanidad en tanto que especie, sin ninguna otra calificación (Westermann 200).

Con posterioridad se hará una nueva operación divina para convertirla en una humanidad sexuada. Esto no es en nada contradictorio con la forma inacabada en que anteriormente es presentada la humanidad en el relato. La diferencia estriba en que el proceso de creación de la humanidad plena se enuncia en diversas fases, revelando que hay una estrategia narrativa puesta en marcha por la voz del relato. Para un análisis antropológico-teológico esta constatación es crucial. El texto muestra también un punto de vista particular del personaje divino que imagina la creación no solamente como algo nuevo, sino también como una transformación compleja. Hay, además, un tercer narrador: el varón, que se representa la acción que acaba de ocurrir (y se la narra a sí mismo), pero de la cual no ha visto sino su resultado: la mujer. Dada su ignorancia del proceso, su narración no es más que su hipótesis del otro que tiene al frente. Desarrollamos estas estrategias en los puntos siguientes.

En segundo lugar, hay que resaltar que este ser humano genéricamente creado aparece a los ojos de Dios en un estado de riesgo vital. El personaje divino enuncia el 
peligro al cual se enfrenta el ser humano usando la expresión hebrea cezer (Génesis $2,18)$, que denota la necesidad de un auxilio sin el cual la vida corre serio peligro (por ejemplo, en Deuteronomio 33, 7; cfr. "Je vais lui faire un allié qui soit son homologue»). Aquello que salvará de la muerte a la humanidad es algo que será un auxilio, que podrá ser mirado cara a cara, con quien pueda tener un contacto visual, como evoca el resto de la expresión hebrea. Ese riesgo vital es entonces la soledad a la que está enfrentada esta humanidad sin alteridad. Por ello, la proposición es crear un «aliado que sea su homólogo», según la traducción propuesta por el recién citado autor. Obviamente no se trata aquí de una muerte en sentido literal, sino de un impedimento a constituirse como un ser humano completo: sin la alteridad homóloga no hay existencia.

En tercer lugar, en coherencia con lo expuesto más arriba sobre la animalidad al interior del humano, Adonay Elohim busca un ser homólogo a la humanidad en la creación de los animales, al igual que ella desde la arcilla, pero no se encuentra allí el auxilio que para la humanidad genérica esperaba. El riesgo vital sigue, entonces, presente.

Finalmente, en cuarto lugar, se realiza la separación al interior de la humanidad genéricamente creada. Lejos de ser una actividad simple, el narrador enuncia la separación en varios pasos. La humanidad es dormida profundamente, lo que equivale a una suspensión de la conciencia (agnosia) y a la limitación de controlar el proceso que se realiza (cfr. Balmary 75). Enseguida, Adonay Elohim toma uno de sus lados, es decir, toma la mitad de la humanidad. Es conveniente señalar aquí que la traducción del vocablo hebreo por «costilla» es totalmente inadecuada. La expresión hebrea significa «lado», como el lado de una montaña o de una cosa (Samuel 16, 13). Véase, además, el comentario de R. Semuel bar Najmani: «significa uno de sus lados, igual que dices: "para el segundo lado del Tabernáculo, por el norte» (Ex 20, 26)» (Vegas Montaner 17, 6). Finaliza esta fase cerrando con carne el lugar.

El narrador cuenta que Adonay Elohim «construye»-como se construye un edificio o metafóricamente «se funda» una familia (cfr. Deuteronomio 25, 9)-, luego de lo cual la lleva al ahora varón, como había hecho con los animales anteriormente (v.29).

En síntesis, el nacimiento de la posibilidad de alteridad se lleva a cabo mediante un proceso complejo que el narrador pone en escena, resaltando la pasividad del humano y la acción de Adonay Elohim de establecer una separación fundamental y vital en el ser humano que lo constituye como varón y mujer, capaz de encontrar ahora -la humanidad completa, no únicamente el varón- el (la) homólogo (a) que lo libere del peligro de muerte. Igual que en el relato anterior, la humanidad -ahora varón y mujer- debe encontrar el equilibrio que permita la relación justa; en ambos casos, el éxito del proyecto humano depende de su realización, el humano pleno está siempre por hacerse.

Presentando las cosas de esta manera, el narrador coloca en primer plano el don que significa el uno para el otro en la primera pareja bíblica. Es aquí donde la 
reacción de los personajes complica la trama del relato, resultando de gran interés para el tema que abordamos. El personaje, masculino ahora en el texto, responde de forma poética:

Y el humano (se) dijo: «iEsta, esta vez, es hueso de mis huesos y carne de mi carne; a esta será llamada «mujer» porque de «varón» ha sido tomada esta!» (Génesis 2, 23).

La reacción es sorprendente, toda vez que el varón parece actuar en total contradicción a lo que un lector atento podría esperar. En efecto, actúa como ignorando su ignorancia, puesto que explica aquello que ve como si pudiera cogerla con su conocimiento, explicándola totalmente e ignorando totalmente la acción de Dios (cfr. Lebrun y Wénin 189). Veamos de cerca este punto. Sin mucha duda, la forma poética del discurso del varón es, además, un monólogo: parece confirmado por la textura y por la forma del discurso. El lector notará que el personaje habla de la mujer en tercera persona. Ahora bien, la tercera persona es usada para hablar de alguien que no está allí o para hablar como si alguien no lo estuviera, es decir, invisibilizándolo. Pero es otro aspecto el más sorprendente. La forma en que el varón enuncia la actividad creadora de Adonay Elohim merece un comentario. La complejidad arriba indicada queda reducida en el enunciado del personaje a un «ha sido tomada»; resaltamos la conjugación impersonal y la reducción al verbo tomar. Entre construir y tomar hay una diferencia enorme, distancia, aquí, por él negada.

Pero hay otros signos de la negación de esa distancia. El ser que se le presenta, el cual ha nacido bajo su estado de suspensión de la conciencia es retratado a partir de él mismo: "es hueso de mis huesos y carne de mi carne [...]". Sorprendente referencia a sí mismo y negación de la diferencia. La mujer es vista desde él, desde lo que él pierde, desde lo que ha salido de él, como si eso fuera lo único que los diferencia. Notable es, además, la lectura sobre sí mismo que realiza: mientras el narrador -fiable en el relato- cuenta que Adonay Elohim tomó el lado del ser humano indiferenciado (la humanidad), el personaje enuncia que ella ha sido tomada de un varón.

La continuación de la frase manifiesta que el varón nomina a la mujer a partir del reconocimiento de parte de la diferencia: «a esta se le llamará «mujer» porque de «varón» ha sido tomada esta». En hebreo «mujer» y «varón» se asemejan en su pronunciación, generando gracias a ello un juego de proximidades semánticas. Pero esta forma de enunciar las cosas sugiere más de lo que la intención consciente quiere: ella es vista como una versión femenina de lo masculino que él es. Nótese que es la primera vez en el relato bíblico que se habla de varón y mujer, la diferencia y la semejanza están, entonces, conceptualizadas bajo la perspectiva del varón, de un personaje del texto con quien el narrador no comparte el mismo grado de fiabilidad y conocimiento. La mujer, en efecto, está siempre aquí en silencio, dejándose atrapar por la codicia verbal y cognitiva del varón. La constitución de la alteridad aparece como una posibilidad débil, bastante frágil y sobre todo trabajosa, puesto que debe enfrentar el miedo de sucumbir frente a la agnocia. De hacerlo, de rendirse frente 
al deseo de conocer la totalidad del otro a partir de sí, se instaura más bien una relación de dominación y sumisión donde únicamente los enunciados de uno existen.

En síntesis, este lector-teólogo que se viene dibujando en la lectura del texto debe enfrentarse a un narrador y fiarse de su palabra. La confianza no es vana sino que se basa tanto en la verosimilitud de lo que cuenta -la coherencia dentro del mundo del relato- como en la credibilidad de su discurso de cara al mundo del lector. La experiencia de la confianza en el narrador se le devuelve como exigencia del uso justo de la palabra: el otro aparece en la palabra, se manifiesta en ella. Así, podemos decir que la relación con el otro se inscribe en el lenguaje y en el cuerpo bajo el signo de la aceptación de una distancia constitutiva y misteriosa a la vez. En el trabajo teológico existe la exigencia, no siempre satisfecha, de la renuncia a un lenguaje omnisciente. Pero también está la aceptación de una determinación corporal, nuestro lenguaje está anclado en la historia y este anclaje nos da limitación y posibilidad; lo dirá así la poetisa en la constatación paradojal de la fuerza y debilidad del ser humano: «mon poids alourdit l'univers» (Koltz).

\subsection{Se busca lector}

En el mismo segmento del texto, encontramos la creación de un nuevo espacio para que el lector elabore el sentido del texto. Aquí se trata, más bien, de una brecha en el relato mismo, un momento donde este queda suspendido y el narrador aparece en toda su brutalidad para interpelar al lector. Este tiene que responder con una acción que va mucho más allá de los límites de la narración, pues es su vida la que está interpelada. Así, el narrador obliga a una lectura actualizante de la palabra. Lo que se acaba de leer ahora tiene que aplicarse a la vida, porque si el relato es un mundo desplegado frente al lector para que lo habite, el mundo del lector es alcanzado por el mundo del relato para discernirlo.

Este narrador, entonces, busca un lector y espera de él una reacción al conflicto desatado en el relato, que consiste en que el humano se niega a reconocer la separación como fundadora de la alteridad. Dado que ambos evitan pronunciar un «tú» de reconocimiento del otro, entonces el narrador irrumpe con su voz: «Por eso varón abandonará su padre y su madre y se unirá a su mujer y ellos serán una carne única» (Génesis 2, 24). El narrador no puede estar hablando aquí de los personajes del relato, pues no hay ni padre ni madre que abandonar, el narrador toma la voz para hacerse notorio en el nivel explícitamente ilocutivo del relato, es al lector a quien se dirige esta voz en tono de advertencia. Si la dificultad del varón es reconocer una alteridad, una distancia, la estrategia será trazar un camino que permita al hombre encontrar su verdadera realización. El camino será largo e implica la toma de distancia de lo que es el hueso y carne del lector: salir de su espacio de seguridad, del espacio de lo conocido de su familia (Lebrun y Wénin 205). Al final de ese viaje habrá una posibilidad de encontrar y de unirse con la mujer de manera balanceada, 
justa y con presencia de reconocimiento mutuo (cfr. Wénin, D’Adam à Abraham ou les errances de l'humain 83-4), pero esto no se puede hacer si no se acepta que se debe renunciar a algo: al dominio del otro, al control total o a la fantasía de ese control. Hay un límite fundante de la alteridad que permite reconocer al otro como un don y no como una extensión de sí.

Esta emergencia del lector la hemos llamado una búsqueda de lector porque, como nos ha recordado el más reciente Concilio, la verdad de la Biblia no es una verdad historiográfica, es una verdad que expresa el querer salvífico de Dios (Concilio Ecuménico Vaticano ii: $\mathbb{S} 11$. Recientemente la cuestión ha vuelto a ser planteada en Vide Rodríguez, como el carácter ilucutivo de la verdad bíblica). Entonces, no es cualquier lector el que es interpelado, es un lector modelado por el sentido del texto para que encuentre una vía de realización, una vía a constituirse en humano pleno tal y cual es el proyecto de Dios en el relato: que el humano no sea para su soledad. La cuestión de la actualización del texto fuera del mundo del relato está planteada en la tradición interpretativa. Los rabinos interpretan esta norma como parte de la legislación de divorcio en caso de conversión de un prosélito casado con una mujer con quien comparte un grado de parentesco, según padre o madre. En la interpretación está implícita la idea de normar la vida del lector (cfr. Vegas Montaner 18, 5). Esto recuerda la vocación soteriológica -si se me permite el término- de toda la teología.

\subsection{La teología de la serpiente}

Corrientemente, se afirma que los primeros capítulos del Génesis narran la creación del humano sin pecado (Génesis 1-2) y la posterior caída a causa de la mujer que, arrastrada por la serpiente, come del fruto del árbol, contrariando así la orden explícita de Adonay (Génesis 3).

A partir de la constatación que hemos hecho más arriba, es necesario relativizar esta interpretación. Si ya en el primer encuentro entre varón y mujer apreciamos una alteridad en problemas, el encuentro entre los humanos y la serpiente no es el punto inicial de una caída: es necesario inscribir su significado en el conjunto de la narración, intentando así dar una explicación en el nivel del registro propio del texto:

${ }^{1}$ Ahora, la serpiente era astuta, más que todos los vivientes de los campos que había hecho Adonay Elohim. Y dijo a la mujer: «Verdaderamente, sí, Elohim ha dicho: «Ustedes no comerán de ninguno de los árboles del jardín» [...]» ${ }^{2} \mathrm{Y}$ la mujer dijo a la serpiente: «Del fruto de los árboles del jardín comemos, ${ }^{3}$ pero del fruto del árbol que está al medio del jardín, Elohim ha dicho: «ustedes no comerán de él y ustedes no lo tocarán o morirán»». ${ }^{4}$ Y la serpiente dijo a la mujer: «Morir ustedes no morirán. ${ }^{5}$ Sí, Elohim sabe que el día en que ustedes coman de él, sus ojos se abrirán y ustedes serán como Elohim conociendo bien y mal».

${ }^{6}$ Y la mujer vio que bien era el árbol para comer y que deseoso era para los ojos y codiciable, el árbol, para tener inteligencia / éxito y ella tomó de su fruto y comió y dio también a su hombre con ella y él comió ${ }^{7}$ y se abrieron los ojos de ellos dos y 
ellos conocieron que estaban desnudos y ellos cosieron hojas de higos y se hicieron taparrabos (Génesis 3, 1-7).

Hay que hacer caso a la indicación de Von Rad: «lo que debe retener nuestra atención es lo que la serpiente dice; no lo que la serpiente es» (Von Rad 106). Bajo ese consejo, apreciemos de cerca el discurso de la serpiente que lleva a la mujer a transgredir el precepto de no comer del árbol de conocer bien y mal. La estrategia que el personaje utiliza para lograr este cambio de conducta entra en el terreno de la sutil manipulación. Veamos con algo de detalle esta estrategia (cfr. Wénin, «Péché des origines ou origine du péché?...» 310-4; D’Adam à Abraham ou les errances de l'humain 98-108).

El narrador introduce un nuevo personaje en el relato indicando una característica: ella es astuta. El lector del texto hebreo notará que hay un juego de palabras entre el final del capítulo anterior y el inicio de este: el varón y la mujer están desnudos el uno frente al otro y la serpiente es presentada como astuta. No solo presenta el narrador a un nuevo personaje, sino que mediante el sonido de las palabras establece una semejanza que para el lector no es extraña, pues la animalidad interior ya ha aparecido en el texto, como hemos visto. Hay una dimensión de la serpiente que es interior al humano. La indicación del narrador en relación a que la serpiente es un ser creado por Elohim refuerza esta presentación. Los exégetas están bien al tanto de la cuestión: recientemente LaCocque (32-4) resume algunas de las posturas y aprovecha el dato desde el punto de vista antropológico.

El discurso con que el animal interpela a la mujer es revelador de su estrategia: «Verdaderamente, sí, Elohim ha dicho: «Ustedes no comerán de ninguno de los árboles del jardín» [...]». Curiosamente, la serpiente cita el precepto que Elohim había enunciado en Génesis 2, 17. Pero ¿es una cita correcta? Las variaciones son indicativas de las estrategias de los personajes (cfr. Alter, The Art of Biblical Narrative 117). El lector está por confrontarse con una verdadera teología, un discurso sobre la palabra de Adonay Elohim según la serpiente, la más astuta de las creaturas. Veamos la siguiente comparación:

\begin{tabular}{|c|c|c|}
\hline $\begin{array}{c}\text { Génesis 2, } \\
16-17\end{array}$ & Elohim: & $\begin{array}{c}\text { De todos los árboles del jardín comer comerás. } \\
\text { Pero del árbol de conocer bien y mal tú no come- } \\
\text { rás, porque el día en que tú comas, morir morirás. }\end{array}$ \\
\hline Génesis 3,1 & Serpiente: & $\begin{array}{r}\text { Ustedes no comerán de ninguno de } \\
\text { los árboles del jardín. }\end{array}$ \\
\hline Génesis 3,3 & Mujer: & $\begin{array}{c}\text { Del fruto del árbol que está al medio del jardín, } \\
\text { Elohim ha dicho: ustedes no comerán de él y } \\
\text { ustedes no lo tocarán o morirán. }\end{array}$ \\
\hline
\end{tabular}

En la boca de la serpiente, el precepto aparece, en primera instancia, mutilado. La serpiente omite del discurso de Dios el deber de comer de todos los árboles del jardín para enfatizar únicamente la imagen de un Dios que restringe. Pero la diferencia más significativa está en la severidad de tal limitación. El humano debe 
consentir un límite para poder vivir, lo hemos planteado más arriba, pero el discurso de la serpiente convierte el límite en una restricción total. Dios no es presentado por la serpiente como un ser que limita para que la vida exista, sino que restringe totalmente y con un sentido de rivalidad. Dios impondría, según la serpiente, una carga al humano y no una vía de salud para él. La serpiente sugiere entonces una imagen de Dios distorsionada, idolátrica finalmente por la reducción a un único aspecto (cfr. Wénin, «Le serpent, le taurillon et le baal...» 28-33).

La astuta serpiente encuentra un eco en la mujer que, inducida por la empatía de la serpiente, contesta citando, esta vez ella, el precepto en cuestión (Génesis 3, 3). El lector es confrontado a un nuevo modelo teológico, esta vez de la parte del humano-mujer. La interpretación del precepto que la mujer realiza muestra la buena marcha de la estrategia de la serpiente, ya que agrega un aspecto de rigor o severidad a la restricción: «ni comer ni tocar». Junto con mutilar, además, la primera parte del precepto, la mujer da cuenta que la serpiente ha logrado disimular la dimensión de gratuidad del don ofrecido por Adonay Elohim en el precepto original. Además, la mujer habla del árbol que está al medio del jardín que según Génesis 2, 9 es el árbol de la vida, no el árbol del conocimiento del bien y mal. Este desplazamiento muestra que la prohibición está en el centro de atención del personaje femenino (Wénin, «Péché des origines ou origine du péché?...» 312). También Von Rad ve algo de esto, pues opina que la misma mujer que quiere imponerse una ley (cfr. El libro del Génesis 106), no obstante, esa ley excesivamente restrictiva ella la enuncia como establecida por Dios, lo cual no hace para nada justicia a la intención del personaje. Enseguida la serpiente reacciona con una jugada final: «Morir ustedes no morirán. Sí, Elohim sabe que el día en que ustedes coman de él, sus ojos se abrirán y ustedes serán como Elohim conociendo bien y mal».

En primer lugar, revierte la consecuencia de comer el fruto: comerlo no provoca la muerte, sino el conocimiento. Nótese que la serpiente presiona sobre la misma tecla sensible del varón en el episodio anterior, a saber, la dificultad de aceptar cierta agnocia. En segundo lugar, reinterpreta la intención de Dios: él habría restringido el acceso a este árbol para evitar que el humano sea como él. Así, la serpiente centra la atención de la mujer sobre la prohibición como expresión de los celos de Dios. En el egoísmo arbitrario de Dios, según la serpiente, el precepto no tiene más sentido que protegerse del mismo humano que ha creado. ¡Toda una teología de la serpiente: Dios teme al humano que crea! De ese temor, siempre según la serpiente y quien asuma su modelo teológico, "Dieu n'est plus qu'un législateur qui se contente d'interdire, qui impose une frustration au désir humain en limitant sa jouissance» (Wénin, "Le récit de Genèse 3...» 312). La cuestión fundamental aquí es la falsedad de la imposición de la frustración, porque el límite se impone como manera de permitir un espacio de reconocimiento, una distancia respetuosa que haga posible la relación. Queda instalado así el miedo al otro o, más profundo todavía, queda instado el otro como amenaza, una especie de rivalidad divina con el humano. El lector atento estará bien pendiente de este modelo teológico vehiculado por un personaje el cual no tiene 
credibilidad en la medida que se ha demostrado un hermeneuta sutilmente torcido, cita las palabras de Elohim para retorcerlas.

Haciendo esto, despierta en la mujer un deseo que afecta a un elemento constitutivo de la humanidad tal y cual aparece en el relato, puesto que aquello que se repite es el conocimiento ( «Elohim sabe [...] ojos se abrirán [...] serán conocedores como Elohim»). La variedad, la pluralidad de la acción divina queda reducida a un celoso Dios-conocimiento. Nada raro que la mujer entre en la lógica de la serpiente y vea el fruto con ojos distintos a la lógica del don. En definitiva, varón y mujer tocan el mismo obstáculo a la hora de constituirse como seres humanos autónomos y reconocientes.

$¿$ Qué ha sido de nuestro lector en este espacio creado por el relato? Confrontado a diversas interpretaciones del actuar divino debe mantenerse en la postura evaluativa a la cual el texto lo tiene ya habituado. Para el lector, una verdad de Dios se revela nada más que en la inscripción de su palabra en la intriga del relato. La prohibición no tiene sentido sin el riesgo vital al cual se enfrente el humano: «si comes, ciertamente morirás». La arbitrariedad del precepto corresponde con la hermenéutica de la serpiente; más de alguna vez la teología le ha creído más a ella que a la voz de Adonay. Por ejemplo, para Von Rad el precepto tiene la única función de resaltar la necesidad de obediencia del humano que se juega su existencia entre ella y la transgresión. En realidad, para ser justos con el texto, la prohibición cuida al humano de engullir al otro.

Anotamos más arriba una palabra que no desarrollamos: idolatría ¿No nos refrenda aquí el texto una función de la teología, la de discernir la idolatría en ella misma? Sería una especie de función crítica que la depura del maquillaje que no deja ver en Dios el rostro de la gratuidad y de la promoción de la vida

Recientemente, Pedro Trigo -en una visita realizada a la Facultad de Teología de la Universidad Católica de Chile- planteó también esta tarea de la teología. Lo había ya dicho:

La primera tradición que debe no solo proseguir sino profundizarse es la que relativiza el estatuto de la teología como un saber provisional, fragmentario, con fuertes dosis proyectivas (y por tanto contaminado de idolatría), y por eso necesariamente plural y en diálogo (no en mera coexistencia pacífica) para que llegue a constituirse como católico; y sin embargo capaz de expresarse con sentido acerca del misterio de salvación revelado en Jesús de Nazaret, que la sobrepasa absolutamente, un saber por eso no absoluto sino histórico, tradicional y eclesial, aunque no fundamentalista, ya que es una función del Espíritu (Situación de la teología al final del siglo xx). 


\section{CONCLUSIONES: TEOLOGÍA IMAGINATIVA}

Dos series de conclusiones. En primer lugar, podemos afirmar que la ficción tiene una función epistemológica: impulsa la producción conocimiento y, aunque mucho de este aprendizaje tiene relación con el ser humano y su comportamiento, es también un conocimiento teológico. Este conocimiento teológico es inseparable del conocimiento antropológico en los términos en que hemos introducido la importancia del registro narrativo para tematizar la relación entre designio divino y libertad humana. El sabio transmite este proverbio sobre la mode(r/l)ación del lenguaje:

En abundancia de palabras no falta la ofensa, el que retiene sus labios es astuto $(\operatorname{Pr} 10,19)$.

El proverbio sirve de horizonte sobre la relación entre lenguaje y teología. Lo hemos visto en la ruta realizada en estas páginas: retener los labios es poder estilizar el discurso, saber dosificar la información. Todo eso es poder producir sabiduría -que es "oferta de sensatez» (Alonso, ¿Dónde está tu hermano? 20) más que conocimiento intelectual- en el otro a quien se dirige el discurso. La instrucción sapiencial puede ser la forma en que primero pensamos como transmisión de sabiduría; pero también la narración estudia esta relación. En los textos explorados hay una forma de hablar del otro, de representarlo: de modelar su figura frente a sí, frente al lector, frente al otro mismo. El caso paradigmático de esto es la separación del humano en varón y mujer y particularmente el caso de la mujer, estilizada narrativamente en múltiples instancias: en el proyecto de Adonay, en el encuentro con el varón, por ella misma y, finalmente, en el espacio evaluativo del lector que aprecia las anteriores en un espacio triangulado para él. La presencia de Adonay implica que la actitud evaluativa del lector es también teológica, en tanto que confronta su proyecto libre con la realización primera y constante de él por parte del humano, varón y mujer, y en relación entre ellos.

Otra serie de conclusiones se desprende de lo anterior: ¿a qué tipo de conocimiento es impulsado el lector?, ¿qué contenido tiene ese conocimiento? Mediante la ficcionalización, el lector evalúa su propia experiencia en contraste con un texto que él considera autoritativo en virtud de su estatus canónico. Tal texto no promueve una lectura cualquiera, por mucho espacio que el lector tenga en la interpretación y por más que el texto ofrezca sentidos múltiples, el lector está guiado hacia la producción y desmontaje de sentidos. En este caso, con la clave de lectura con que se nos han ofrecido los textos, emerge un cierto andamiaje de relaciones entre los personajes. Esas relaciones son tematizadas como universales en tanto que le pertenecen al humano primordial y en tanto que el lector y la lectora puede reconocerlas en sí mismo (a).

Esta estructura humana en el proyecto de Adonay se organiza en una tensión entre don y ley. El otro es don y alteridad proyectada, pero debe ser recibida como tal y reconocida. Paradojalmente el precepto obliga al don porque protege de la codicia de engullir la diferencia del otro. Si el relato coloca en escena tal proyecto y 
más bien su fracaso que su éxito es porque don y ley no se imponen en el humano desde el exterior, sino que la existencia de la humanidad se juega en la elaboración de la distancia-separación como alteridad justa y reconocida. Aquí no hay triunfalismos anticipados, el humano nace arriesgado a un fracaso que debe necesariamente atravesar y enfrentar para abrirse a la fiesta del otro. De tal tipo es el conocimiento teológico que aporta el texto, una verdad sobre la constitución del humano en el proyecto de Adonay, una verdad de la hechura del humano frente a la existencia de Dios que lo crea.

\section{REFERENCIAS}

Alonso Schökel, Luis. «Una oferta de sensatez. Ensayo sobre la literatura sapiencial». Sapienciales I. Proverbios. Eds. Luis Alonso Schökel y José Vilchez Lindez. Madrid: Cristiandad, 1984. 17-37. Medio impreso.

---. ¿Dónde está tu hermano? Textos de fraternidad en el libro del Génesis. Navarra: Verbo Divino, 1997. Medio impreso.

Alter, Robert. The Art of Biblical Narrative. New York: Basic Books, 1981. Medio impreso.

---. Genesis. Translation and commentary. Nueva York y Londres: W. W. Norton, 1996. Medio impreso.

Balmary, Marie. La divine origine. Dieu n'a pas créé l’homme. París: Gresset \& Fasquelle, 1993. Medio impreso.

Bar-Efrat, Shimon. "Narrative Art in the Bible». Journal for the Study of the Old Testament, Supplement Series 70 (1984). Medio impreso.

Barthes, Roland. Le plaisir du texte. París: Seuil, 1973. Medio impreso.

Barton, John, ed. La interpretación bíblica, hoy. Trad. José Pedro Tosaus Abadía. Maliaño: Sal Terrae, 2001. Medio impreso.

Beauchamp, Paul. La Legge di Dio. Trad. Marco Gambarino. Casale Monferrato: Piemme, 2001. Medio impreso.

Brenner, Athalya. The Intercourse of Knowledge. On Gendering Desire and «Sexuality» in the Hebrew Bible. Leiden: Brill, 1997. Medio impreso.

Cohn, Dorrit. Le propre de la fiction. Trad. Claude Hary-Schaeffer. París: Seuil, 2001. Medio impreso.

Colodenco, Daniel. Génesis: el origen de las diferencias. Buenos Aires: Lilmod, 2006. Medio impreso.

Concilio Ecuménico Vaticano ii (Abrev. DV). «Constitución dogmática «Dei Verbum» sobre la divina revelación». Constituciones. Decretos. Declaraciones. Trad. Lorenzo Amigo Espada y Rosa María Herrera García. Madrid: Biblioteca de Autores Cristianos, 2000. 179-207. Medio impreso.

Donaldson, Mara E. «Bordercrossing: Fall and Fantasy in Blade Runner and Thelma and Louise». The Monstrous and the Unspeakable. The Bible as Fantastic Literature. 
Eds. George Aichele y Tina Pippin. Sheffield: Sheffield Academic Press, 1997. 19-42. Medio impreso.

Eco, Umberto. Lector in fabula. La cooperazione interpretativa nei testi narrativi. Milano: Bompiani, 2000. Medio impreso.

Fokkelman, Jan P. Reading Biblical Narrative. An Introductory Guide. Trad. Ineke Smit. Louisville, KY: Westminster-John Knox Press, 1999. Medio impreso.

Genette, Gérard. Nuevo discurso del relato. Trad. Marisa Rodríguez Tapia. Madrid: Cátedra, 1998. Medio impreso.

Gesché, Adolphe. «Pour une identité narrative de Jésus». Revue théologique de Louvain 30 (1999). 153-179 y 336-56. Medio impreso.

Gunn, David. «The Fate of King Saul. An Interpretation of a Biblical Story». Journal for the Study of the Old Testament, Supplement Series 14 (1980). Medio impreso.

Gándara, Alejandro. Las primeras palabras de la creación. Barcelona: Anagrama, 1998. Medio impreso.

Hamilton, Victor P. The Book of Genesis. Chapters 1-17 (The New International Commentary on the Old Testament). Grand Rapids, MI: Eerdmans, 1990. Medio impreso.

Koehler, Ludwig y Walter Baumgartner. The Hebrew \& Aramaic Lexicon of the Old Testament. Trad. Richardson. Leiden: Brill, 2000. CD-ROM.

Koltz, Anise. Béni soit le serpent. Poèmes. Esch-sur-Alzette y Québec: Phi-Les écrits des forges, 2004. Medio impreso.

LaCocque, André. "Crepe nel muro». Comme pensa la Bibbia. Studi esegetici ed ermeneutici Eds. André LaCocque y Paul Ricœur. Trad. Franco Bassani. Brescia: Paideia, 2002. 23-48. Medio impreso.

Lebrun, Jean-Pierre y André Wénin. Des lois pour être humain. Ramonville Saint Agne: Érès, 2008. Medio impreso.

Macdonald, Margaret. «Le langage de la fiction». Esthétique et Poétique. Ed. Gérard Genette. París: Seuil, 1992. 203-28. Medio impreso.

Marguerat, Daniel e Yvan Bourquin. Cómo leer los relatos bíblicos. Iniciación al análisis narrativo. Maliaño: Sal Terrae, 2000. Medio impreso.

Mirguet, Françoise. «Gn 21-22: Maternité et paternité à l'épreuve. Les personnages comme clef de lecture». Études théologiques et religieuses 79 (2003). 307-28. Medio impreso.

Mura, Gaspare. Ermeneutica e verità. Storia e problemi del la filosofia del l'interpretazione. Roma: Città Nuova, 1997. Medio impreso.

Navajas, Gonzalo. Mímesis y cultura en la ficción. Teoría de la novela. Londres: Tamesis Books, 1985. Medio impreso.

Di Pede, Elena. «Vivre ensemble. Quelques pistes bibliques de réflexion». Études théologiques et religieuses 82 (2007). 533-48. Medio impreso.

Pontificia Comisión Bíblica. La interpretación de la Biblia en la Iglesia. Santiago: San Pablo- Paulinas, 1994. Medio impreso. 
Von Rad, Gerhard. El libro del Génesis. Trad. Santiago Romero. Salamanca: Sígueme, 1988. Medio impreso.

Ratzinger, Joseph. La interpretación bíblica en crisis. Problemas del fundamento y la orientación de la exégesis de hoy. Trad. Juan Carlos Len Álvarez. Lima: Vida y Espiritualidad, 1995. Medio impreso.

Rendtorff, Rolf. «The Paradigm is Changing: Hopes and fears». Biblical Interpretation 1 (1993). 34-53. Medio impreso.

Ricœur, Paul. «Le récit interpretatif. Exégèse et Théologie dans les récits de la Passion». Recherches de Science Religieuse 73 (1985). 17-38. Medio impreso.

Saer, Juan José. El concepto de ficción. Buenos Aires: Espasa Calpe-Ariel, 1997. Medio impreso.

Ska, Jean-Louis, Jean-Pierre Sonnet y André Wénin. Análisis narrativo de relatos del Antiguo Testamento. Navarra: Verbo Divino, 2001. Medio impreso.

Ska, Jean-Louis. "Je vais lui faire un allié qui soit son homologue»(Gn 2,18). A propos du terme 国ezer -«aide». Biblica 65 (1984). 233-8. Medio impreso.

---. "Our Fathers Have Told Us». Introduction to the Analisis of Hebrew Narrative (Subsidia Biblica 13). Roma: Pontificio Istituto Biblico, 1990. Medio impreso.

Sonnet, Jean-Pierre. «Narration biblique et (post)modernité». La Bible en récits. L'exégèse biblique à l'heure du lecteur. Colloque international d'analyse narrative des textes de la Bible, Lausanne (mars 2002). Ed. Daniel Marguerat. Genève: Labor et fides, 2003. 253-63. Medio impreso.

Sternberg, Meir. The Poetics of Biblical Narrative. Ideological Literature and the Drama of Reading. Bloomington, IN: Indiana University Press, 1985. Medio impreso.

Van Treek Nilsson, Mike. "Amnón y Tamar (2 S 13,1-22). Ensayo de antropología narrativa sobre la violencia». Estudios Bíblicos 65 (2007). 3-32. Medio impreso.

Trigo, Pedro. "Situación de la teología al final del siglo xx». Revista electrónica latinoamericana 215. Fecha de ingreso: 2 de octubre de 2009. < http://www.webcitation. org/5upTBhYHv>. Sitio web.

Vegas Montaner, Luis, ed. Génesis Rabbah I (Génesis 1-11). Comentario midrásico al libro del Génesis. Navarra: Verbo Divino e Institución San Jerónimo, 1994. Medio impreso.

Vide Rodríguez, Vicente. "La verdad contenida en la Biblia: en qué consiste y en qué estratos del lenguaje se encuentra». Estudios eclesiásticos 83 (2008). 271-304. Medio impreso.

Wénin, André. «De la violence à l'alliance. Un chemin éthique inspiré des écritures». Revue d'éthique et de théologie morale «Le Supplément» 213 (2000). 105-23. Medio impreso.

---. «Le serpent, le taurillon et le baal. Variations sur l'idolâtrie dans le Premier Testament». Revue théologique de Louvain 34 (2003). 27-42. Medio impreso.

---. Joseph ou l'invention de la fraternité (Genèse 37-50). Bruxelles: Lessius, 2005. Medio impreso. 
---. D'Adam à Abraham ou les errances de l'humain. Lecture de Genèse 1, 1-12, 4. París: Cerf., 2007. Medio impreso.

---. « «Dieu qui visite la faute des père sur les fils» (Ex 20, 5). En marge d'un livre récent de B.M. Levinson». Revue théologique de Louvain 38 (2007b). 67-77. Medio impreso. ---. El hombre bíblico. Interpretación del Antiguo Testamento. Trad. Ana Pinedo. Bilbao: Mensajero, 2007c. Medio impreso.

---. «Péché des origines ou origine du péché? Le récit de Genèse 3: approche narrative et interprétation». Estudios Bíblicos 65 (2007d). 307-19. Medio impreso.

Westermann, Claus. Genesis 1-11. A Commentary. Trad. John J. Scullion. Minneapolis: Augsburg, 1984. Medio impreso.

Recepción: Mayo 2011

Aceptación: Enero 2012 